\title{
Zersetzung der a- und b-phosphorsauren Salze, der Cyan-, Ferrocyan- und Schwefelcyanverbindungeu und der Alkaloide in wässeriger lösung bei hoher Temperatur in verschlossenen Gefässen.
}

Nach Alvaro Reynoso erleiden die genannten Verbindungen, mit Wasser in Glasröhren eingeschmolzen und unter besonderen Vorsichtsmaassregeln gegen gefährliche Explosionen mehrere Stunden lang auf $280^{\circ} \mathrm{C}$. erhitzt, folgende Zersetzungen.

1) Pyrophosphorsaure Salze. Pyrophosphorsaures Kali und Natron gehen in gemeinphosphorsaures Kali oder Natron über.

Pyrophosphors. Zinkoxyd, Silberoxyd, Kobaltoxyd, Nickeloxyd, Cadmiumoxyd liefern unlösliche drittelphosphorsaure Salze und gelöst bleibende saure einfachphosphorsaure Salze.

Pyrophosphorsaures Bleioxyd, Kupferoxyd, Eisenoxydul und Eisenoxyd geben ebenfalls drittelphosphorsaure Salze und saure einfachphosphorsaure Salze, allein die letzteren zerlegen sich mehr oder weniger in drittelphosphorsaure Salze und freie Phosphorsäure; es bleibt deshalb oft nur wenig Basis in der wässerigen Lösung zurück.

Pyrophosphorsaures Uranoxyd und pyrophosphorsaurer Kalk geben drittelphosphorsaure Salze und reine Phosphorsäure bleibt in Lösung. Beim Kalksalze bleiben nur Spuren von Kalk in Lösung zurück.

Saurer phosphorsaurer Kalk wird auf ähnliche Weise zerlegt, jedoch langsamer und unvollständig.

Die abgesohiedenen drittelphosphorsauren Salze enthalten sämmtlich Wasser und sind meistens krystallisirt, so drittelphosphorsaures $\mathrm{CuO}, \mathrm{CoO}, \mathrm{ZnO}, \mathrm{PbO}$ und $\mathrm{CaO}$. Letzterer in rectangulären Tafeln oder undeutlich ausgebildeten Prismen.

Das drittelphosphorsaure Silbernxyd wird beim Erhitzen dunkelorangeroth, beim Erkalten wieder gelb.

Die gebildeten sauren Phosphate werden durch absoluten Alkohol aus ihrer wässerigen Lösung beinahe vollständig gefällt; die Niederschläge sind drittelphosphorsaure Salze, in Lösung bleibt freie Phosphorsäure mit sebr kleinen Mengen von Basis. Das so gefällte Kobaltsalz hat die Formel $3 \mathrm{CoO}, \mathrm{PO}^{5}+8 \mathrm{HO}$, das Zinksalz $3 \mathrm{ZnO}, \mathrm{PO}^{5}+6 \mathrm{HO}$. Die wässerigen Lösungen der sauren Phosphate lösen drittelphosphorsaure Salze auf und 
lassen sie bein Erhitzen zum Sieden wieder fallen. Sie sind sämmtlich gummiartig.

2) Metaphosphorsaure Salze mit Wasser auf $280^{\circ} \mathrm{C}$. erhitzt, zerlegen sich in drittelphosphorsaure Salze, einfachphosphorsaure Salze und freie Phosphorsäure.

Zuweilen zerlegen sich auch die einfachsauren Salze wieder in drittelsaure und in freie Phosphorsäure. So der metaphosphorsaure Kalk, nach folgender Gleichung: $6\left(\mathrm{CaO},{ }^{\mathrm{a}} \mathrm{PO}^{5}\right)+12 \mathrm{HO}=2\left(3 \mathrm{CaO}^{\mathrm{c}} \mathrm{PO}^{5}\right)+4\left(3 \mathrm{HO},{ }^{\mathrm{cPO}}{ }^{5}\right)$.

3) Cyanverbindungen. Jodcyan liefert Jodammonium und Kohlensäure.

Bromcyan giebt Bromammonium und Kohlensäure.

Schwefelcyankalium giebt Schwefelammonium and doppelt-kohlensaures Kali.

Kaliumeisencyanür und Kaliumeisencyanid geben ameisensaures Kali, kohlensaures Ammoniak und Eisenoxyd.

Cyansilber giebt kohlensaures Ammoniak und krystallisirtes Silber.

Cyanquecksilber liefert kohlensaures Ammoniak und metallisches Quecksilber.

4) Alkaloide. Narcotin liefert Metacetamin; Chinin giebt Chinolin. (Ann. de Chim. et de Phys. 3. Sér. Sept. 1855. Tom. XLV. p. 107-112.) Dr. H. Ludwig.

\section{Zubereitung der vegetabilischen Kohle, um ihr das Cutfärbungsvermögen der thierischen Kohle zu geben.}

J. Stenhouse nimmt zu diesem Zweck auf 92,5 Th. Kohle 7,5 Th. phosphorsauren Kalk, löst den letzteren in $20 \mathrm{Th}$. Salzsäure auf, verdïnnt die lösung mit $40 \mathrm{Th}$. Wasser und kocht die Kohle mit dieser Flüssigkeit. Nach dem Kochen wird die Kolle getrocknet und gegliiht, worauf sie zur Anwendung tauglich ist.

Will man Kohle durch Impriigniren mit Thonerde zum Entfärben geeignet machen, so erhitzt man dieselbe mit einer Lösung von schwefelsaurer Thonerde oder Chloraluminium, so dass die darin enthaltene Thonerde 7,5 Th. auf 92,5 Th. Kohle beträgt. Dic Kohle wird hierauf getrocknet und gegliiht. (Le Technologiste. Octbr. 1856. pag. 13. - Polyt. Centrbl. 1857. S. 77.)

E. 